Florida International University

FIU Digital Commons

FIU Electronic Theses and Dissertations

University Graduate School

3-28-2019

\title{
A Constructal Approach to the Design of Inflected Airplane Wings
}

Shanae Powell

Florida International University, spowe020@fiu.edu

Follow this and additional works at: https://digitalcommons.fiu.edu/etd

Part of the Aerodynamics and Fluid Mechanics Commons, Aeronautical Vehicles Commons, Applied Mechanics Commons, Computer-Aided Engineering and Design Commons, Energy Systems Commons, Other Aerospace Engineering Commons, and the Structures and Materials Commons

\section{Recommended Citation}

Powell, Shanae, "A Constructal Approach to the Design of Inflected Airplane Wings" (2019). FIU Electronic Theses and Dissertations. 4013.

https://digitalcommons.fiu.edu/etd/4013

This work is brought to you for free and open access by the University Graduate School at FIU Digital Commons. It has been accepted for inclusion in FIU Electronic Theses and Dissertations by an authorized administrator of FIU Digital Commons. For more information, please contact dcc@fiu.edu. 


\title{
FLORIDA INTERNATIONAL UNIVERSITY
}

\author{
Miami, Florida
}

A CONSTRUCTAL APPROACH TO THE DESIGN OF INFLECTED AIRPLANE WINGS

A thesis submitted in partial fulfillment of the

requirements for the degree of

MASTER OF SCIENCE

in

MECHANICAL ENGINEERING

by

Shanae Powell

2019 


\section{To: Dean L. Volakis}

College of Engineering

This thesis, written by Shanae Powell, and entitled A Constructal Approach to the Design of Inflected Airplane Wings, having been approved in respect to style and intellectual content, is referred to you for judgment.

We have read this thesis and recommend that it be approved.

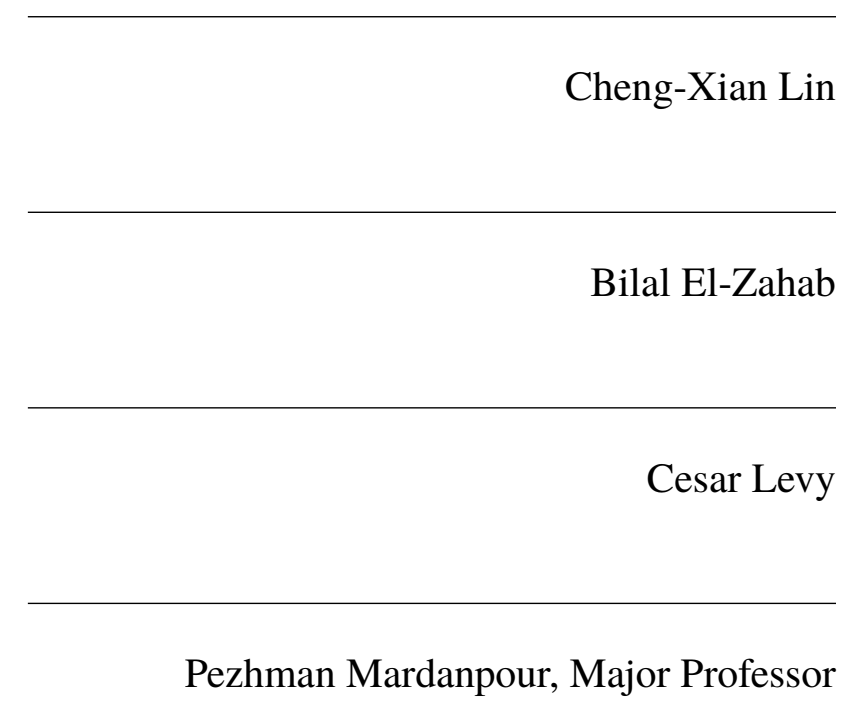

Date of Defense: March 28, 2019

The thesis of Shanae Powell is approved.

\begin{tabular}{r} 
Dean John Volakis \\
College of Engineering \\
\hline Andres G. Gil \\
and Dean of the University Graduate School
\end{tabular}

Florida International University, 2019 
(C) Copyright 2019 by Shanae Powell

All rights reserved. 


\section{DEDICATION}

I dedicate this thesis to my family. Without their prayers, support and love, the completion of this work would not have been possible. 


\section{ACKNOWLEDGMENTS}

I wish to thank the members of the Fluid Structure Interaction Lab- Ehsan Izadpanahi and Dr. Siavash Rastkar, for teaching me the necessary software programs, giving guidance, sharing their knowledge and availing themselves to help throughout this entire research. I would also like to thank my major professor, Professor Pezhman Mardanpour who has provided the resources, intellectual guidance and engineering expertise needed to bring this project to completion. Thank you to the members of my committee for their willingness to be a part of my thesis journey.

This Master's program has pushed me to higher heights of knowledge and has equipped me with the tools needed to explore even deeper levels of research. 


\author{
ABSTRACT OF THE THESIS \\ A CONSTRUCTAL APPROACH TO THE DESIGN OF INFLECTED AIRPLANE \\ WINGS $^{1}$ \\ By \\ Shanae Powell \\ Florida International University, 2019 \\ Miami, Florida \\ Professor Pezhman Mardanpour, Major Professor
}

Aeroelastic instabilities such as flutter can be accurately captured by state-of-the-art aeroelastic analysis methods and tools. However, these tools and methods fall short in exposing the reasons behind the occurrence of such instabilities. In this research, the constructal law is used to determine the main cause of the variation in the flutter speed and stress distribution for inflected aircraft wings. This law considers the design as a physics phenomenon and uses an evolutionary flow principle to explain and predict the occurrence of energy flow configurations (i.e., the flow of stresses throughout the structure). For this study, a flying wing aircraft with different flap-wise wing inflection is considered. The sectional properties for the flying wing aircraft configurations are obtained from Variational Asymptotic Beam Sections (VABS ${ }^{\mathrm{TM}}$ ) and aeroelastic stability analyses performed in NATASHA (Nonlinear Aeroelastic Trim And Stability of HALE Aircraft). Finally, VABS ${ }^{\mathrm{TM}}$ recovers the flow of stresses throughout the wings. The stability and stress analyses provide insight into the changes in the flow of stresses as the geometry changes. Structural analyses reveal that inflection of the wings has the potential to "smooth out" the flow of stresses i.e., the inflected configuration allows for easier access to the flow of stresses and avoids stress strangulation (stress concentration). It is this configuration that is most stable.

\footnotetext{
${ }^{1}$ Parts of this thesis are from "Constructal Approach to the Design of Inflected Airplane Wings." Shanae Powell, Ehsan Izadpanahi, Siavash Rastkar, Pezhman Mardanpour; reprinted by permission of the American Institute of Aeronautics and Astronautics, Inc.[1]
} 


\section{TABLE OF CONTENTS}

CHAPTER

PAGE

1 INTRODUCTION . . . . . . . . . . . . . . . . . . . 1

1.1 Aeroelasticity and Aeroelastic Instability . . . . . . . . . . . . . . 1

1.2 Flow of Stresses . . . . . . . . . . . . . . . . . . . 2

1.3 Contribution of the Present Work . . . . . . . . . . . . . . . 3

1.4 Statement of the Problem . . . . . . . . . . . . . . . . . 4

1.5 Research Questions and Objectives . . . . . . . . . . . . . . 4

2 LITERATURE REVIEW . . . . . . . . . . . . . . . . . . 6

2.1 Constructal Law . . . . . . . . . . . . . . . . . . 6

2.2 Previous Work . . . . . . . . . . . . . . . 7

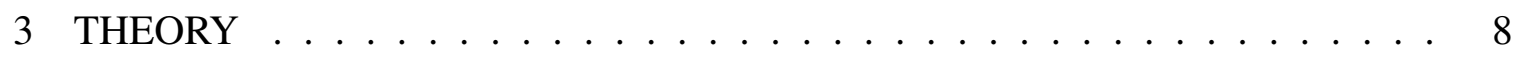

3.1 Aeroelastic Theory ................... 8

3.1.1 Structural Theory: Nonlinear Composite Beam Theory . . . . . . . 8

3.1.2 Aerodynamic Theory: 2D Induced Flow Theory of Peters . . . . . . 10

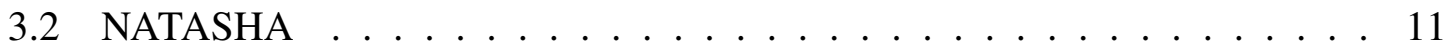

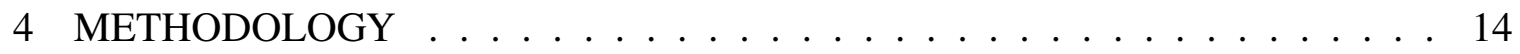

4.1 Software ............................... 14

$4.1 .1 \mathrm{Gmsh} \ldots \ldots \ldots \ldots \ldots \ldots$

4.1.2 Variational Asymptotic Beam Sectional Analysis $\left(\mathrm{VABS}^{\mathrm{TM}}\right)$. . . . 14

4.1 .3 NATASHA ......................... 14

4.2 Stress Recovery Procedure . . . . . . . . . . . . . . . 15

4.3 Case Study . . . . . . . . . . . . . . . . . . 15

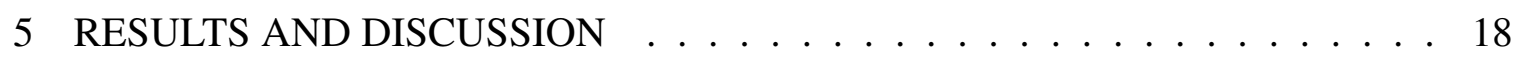

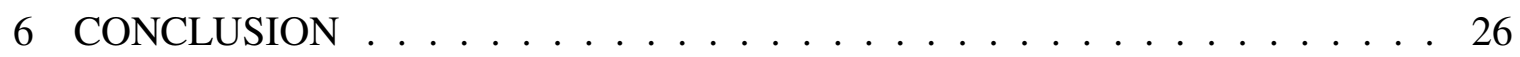

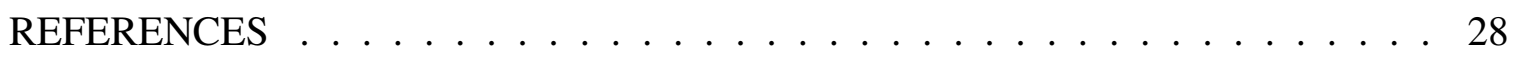




\section{LIST OF FIGURES}

FIGURE

PAGE

1 Schematic of the field of aeroelasticity . . . . . . . . . . . 2

2 The essential features of beam kinematics. . . . . . . . . . . . . . 8

3 Design generation and analysis process. . . . . . . . . . . 15

4 Schematic view of flying wing aircraft without curvature. . . . . . . . . 16

5 Schematic view of inflected flying wing aircraft. . . . . . . . . . 16

6 The unstable symmetric free-free mode shape of the base model flying wing. 18

7 Eigenvalue analysis of base model flying wing. . . . . . . . . . . 20

8 Stress distribution for the flying wing, $\sigma_{11}(\mathrm{~Pa}) \ldots \ldots \ldots 22$

9 Stress distribution for the flying wing, $\sigma_{12}(\mathrm{~Pa}) \ldots \ldots \ldots 23$

10 Stress distribution for the flying wing, $\sigma_{13}(\mathrm{~Pa}) \ldots \ldots \ldots 24$

11 Stress distribution for the flying wing, Von Mises $(\mathrm{Pa}) \ldots \ldots \ldots$ 


\section{NOMENCLATURE}

()$^{\prime} \quad$ Partial derivative with respect to $\mathbf{x}_{1}$

$\bar{k} \quad$ Normalized column vector of an undeformed beam's initial curvature and twist measures in $\mathbf{b}_{\mathbf{i}}$ basis

$\Delta \quad$ Identity matrix

() Partial derivative with respect to time

$\kappa \quad$ Column vector of elastic twist and curvature measures (one-dimensional generalized moment strain measures)

$\gamma \quad$ Column vector of one-dimensional generalized force strain measures

$\mathbf{B}_{\mathbf{i}} \quad$ Unit vectors of a deformed beam's cross-sectional frame of reference in which $i$ is equal to $1,2,3$

$\mathrm{b}_{\mathrm{i}} \quad$ Unit vectors of an undeformed beam's cross-sectional frame of reference in which $i$ is equal to $1,2,3$

$\mathbf{F} \quad$ Column vector of inertial force measures in $\mathbf{B}_{\mathbf{i}}$ basis

$\mu \quad$ Mass per unit length

$\Omega \quad$ Column vector of cross-sectional angular-velocity measures in $\mathbf{b}_{\mathbf{i}}$ basis

() Nodal variable

$\xi \quad$ Column vector of center-of-mass offset from the frame of reference origin in $\mathbf{b}_{\mathbf{i}}$ basis

$B \quad$ Deformed beam's cross-sectional frame of reference

$b \quad$ Undeformed beam's cross-sectional frame of reference

C Transformation matrix

c Chord

$e_{1} \quad$ Column vector $\left[\begin{array}{lll}1 & 0 & 0\end{array}\right]^{T}$

$f \quad$ Column vector of distributed, applied force measures in $\mathbf{B}_{\mathbf{i}}$ basis

$H \quad$ Column vector of cross-sectional angular-momentum measures in $\mathbf{B}_{\mathbf{i}}$ basis

I Cross-sectional inertia matrix for deformed beam

$i \quad$ Cross-sectional inertia matrix for undeformed beam

$i_{i} \quad$ Unit vectors for inertial frame of reference in which $i$ is equal to $1,2,3$ 
$K \quad$ Column vector of a deformed beam's curvature and twist measures in $\mathbf{B}_{\mathbf{i}}$ basis

$k \quad$ Column vector of an undeformed beam's curvature and twist measures in $\mathbf{b}_{\mathbf{i}}$ basis

$M \quad$ Column vector of internal-moment measures in $\mathbf{B}_{\mathbf{i}}$ basis

$m \quad$ Column vector of distributed, applied-moment measures in $\mathbf{b}_{\mathbf{i}}$ basis

$n \quad$ Number of elements

$P \quad$ Column vector of cross-sectional linear-momentum measures in $\mathbf{B}_{\mathbf{i}}$ basis

$r \quad$ Column vector of position-vector measures in $b_{i}$ basis

$u \quad$ Column vector of displacement vector measured in $b_{\mathbf{i}}$ basis

$V \quad$ Column vector of velocity measured in $\mathbf{B}_{\mathbf{i}}$ basis

$x_{1} \quad$ Axial coordinate of beam 


\section{INTRODUCTION}

The initial and continuous design of an airplane has its roots in the study and mimicking of nature such as birds [2,3] and sea creatures [4]. Thus, the study and design of airplane wings with curvature is nothing new as there exists research for airplane wings with curvature in the chord-wise direction [5-10], span-wise direction [7, 10], at the leading edge [11-13], in the flap-wise direction [10], and numerous other curvature designs [2]. The inflected wing studied in this paper was inspired by the work of NASA [10]. Their main purpose was to investigate the effects of curvature in the flap-wise direction (inflection and drooping) of an airplane's wings on lift and drag. Their findings demonstrated that curvature reduced the lift and drag. This research takes it a step further to conduct aeroelastic analyses on inflected wing configurations. Current aeroelastic analysis and design methods can accurately capture aeroelastic instabilities such as divergence and flutter. However, they fall short in elucidating the reasons for the occurrence of such instabilities.

\subsection{Aeroelasticity and Aeroelastic Instability}

With a great focus on the design of airplane wings to achieve efficiency, different wing designs have been explored but the quest to obtain more efficient designs almost always results in a trade-off. For the design of modern flying wing aircraft, one of the biggest trade-offs is flexibility for aeroelastic problems. The field of aeroelasticity covers dynamics, elasticity and aerodynamics as presented in Fig. 1 [14]. From this figure, an interaction among aerodynamic, inertial, and elastic forces is categorized as a dynamic aeroelastic phenomenon whereas an interaction between elastic and aerodynamic forces is referred to as static aeroelasticity. Flutter, for example, is a dynamic aeroelastic instability.

Flying wing aircraft have very flexible wings and are desirable especially for purposes such as surveillance. Despite the benefits they provide, flexible aircraft are prone to experiencing aeroelastic instabilities while in flight. This instability can be as a result of the aircraft not being able to compensate for the aerodynamic, elastic and inertial forces that 


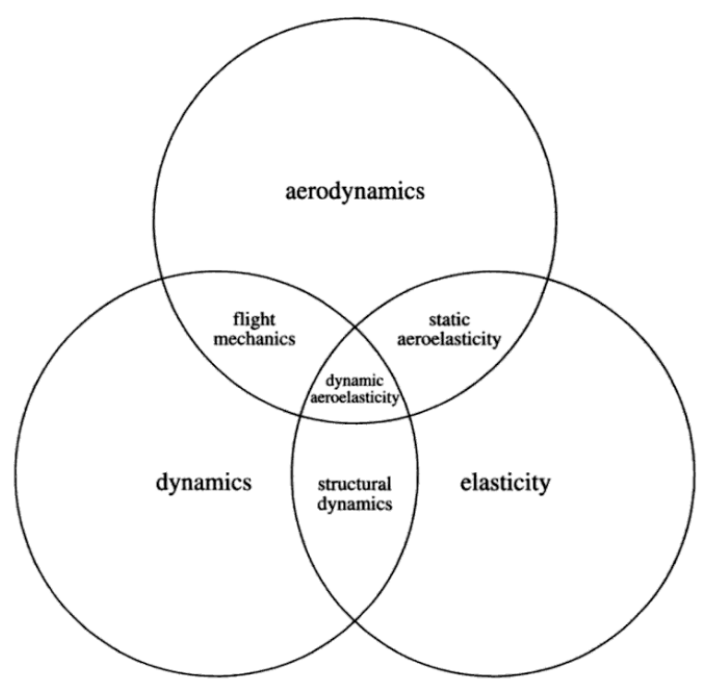

Fig. 1: Schematic of the field of aeroelasticity

act on it. Aeroelastic problems, according to Bisphinghoff et al. [15], occur "when structural deformations induce additional aerodynamic forces." They went on further to say that these "forces may produce additional structural deformations which will induce still greater aerodynamic forces." There is a possibility that these forces may die out and reach stability or they may diverge and cause catastrophe. Several approaches that have been taken to solve the problem of aircraft flutter include "modifying the structure, adding mass balance, imposing flight restrictions" and the use of active flutter suppression systems [16] with each having its own limitations. The flutter boundary is greatly affected by the engine or store location according to Refs. [17-19] which Mardanpour et al. [20, 21] have shown by changing the location of the engine on an airplane wing to avoid flutter. They also found that sweep can significantly increase flutter and divergence speed.

\subsection{Flow of Stresses}

The concept of "flow of stresses" was initially introduced by Lorente et al.[22]. They investigated and demonstrated the analogy between "the configuring of heat and fluid flow and the configuring of the flow of stresses" and revealed that the avoidance of flow strangu- 
lation is the common principle between both. In light of the constructal law, viewing solid structures as flow systems that configure and morph to accommodate the flow of stresses, they formulated a methodology for the modeling of solid structures in which stresses flow without strangulation. This led to the conclusion that such structures were the strongest, lightest and for heat transfer and fluid flow- the most efficient. Additionally, for the analysis of the Y-shaped structure, to allow the stresses to flow so that the load is maximal when the volume is fixed and the volume is minimal when the load is fixed, the best design under varying failure mechanisms (such as buckling, pure compression and pure tension) differed depending on the failure mechanism. Thus, for design-generation, the flow of stresses play a vital role in the transference of mass more easily on the landscape [23].

According to Bejan [23], "the constructal law is the law of physics that accounts for the natural tendency of all flow systems (animate and inanimate) to change into configurations that offer progressively greater flow access over time." It is self-standing and attributes the existence of design and pattern in nature to a law of physics. The "Constructal theory is the view that the generation of flow configuration is a universal phenomenon of all physics" [24]. Advancement of research and design using the constructal law are provided in Refs. [25-28].

\subsection{Contribution of the Present Work}

The main aim of this research is to investigate the reasons for the occurrence of aeroelastic instabilities such as flutter, by studying an airplane with inflected wings. Application of the constructal law [29] and the flow of stresses [22] sheds light on this phenomenon. For this study, the flutter characteristics and the flow of stresses of the base model, a flying wing aircraft, are compared to similar configurations with the added feature of flap-wise curvature (inflection) of the wings. To create each model, the sectional geometry of the fuselage and the wings are created in Gmsh (a 3D finite element mesh generator with integrated CAD 
engine and post-processor). The structural properties of each model are then obtained in Variational Asymptotic Beam Sectional Analysis (VABS ${ }^{\mathrm{TM}}$ ) which are imported into Nonlinear Aeroelastic Trim And Stability of HALE Aircraft (NATASHA) for stability analysis. NATASHA is a computer program written in MATLAB and is based on Hodges nonlinear composite beam theory [30]. It produces the trim state solutions which are imported back to $\mathrm{VABS}^{\mathrm{TM}}$ for stress recovery.

\subsection{Statement of the Problem}

HALE aircraft have become desirable and of high importance owing to their highaspect-ratio wings. In order to obtain this high-aspect-ratio and meet weight stipulations, the

wings are very flexible. Flexibility may cause aeroelastic problems such as flutter. These problems cannot be overlooked as they can cause catastrophes when the airplane can no longer compensate for the external factors that act on it and continue to be level in flight. In order to avoid or minimize as best as possible the problem of instability, the root aeroelastic problems have to be addressed first. Understanding how stresses flow in a wing with an unconventional curvature such as inflection through the lens of the constructal law, will provide a better understanding of the causes of such instabilities and a solution.

\subsection{Research Questions and Objectives}

This study addresses the following questions:

1. Do inflected airplane wings accommodate the flow of stresses better than wings that are not inflected? "Better" being measured by the distribution of localized stresses and avoidance of flow strangulation.

2. Does the angle of inflection of the airplane wing affect its flutter speed?

3. Can the constructal law explain any difference in the flow of stresses and the flutter speed for inflected and uninflected airplane wings? 
The objectives of this study are to:

1. Study the flow of stresses in flying wing aircraft with varying angles of flap-wise curvature (inflection).

2. Invoke the constructal law to explain any difference in the distribution of the flow of stresses in the wings.

3. Investigate the effects of inflection on the flutter speed of a flying wing aircraft. 


\section{LITERATURE REVIEW}

\subsection{Constructal Law}

The Constructal law was birthed from the understanding that "design" is a universal phenomenon. This phenomenon has not been accounted for in the laws of thermodynamics where the first law accounts for the conservation of energy and the second law irreversibility in any system. The "any system" being a black box. These two laws of thermodynamics govern the nature of flows in and out of a system but do not shed light on the configuration of what is inside. Nature on the other hand is configured- it has shape and structure [31]. Bejan [32] points out that "the laws of thermodynamics do not account completely for the systems of nature." In order to do so, thermodynamics need to be "strengthened with an additional self-standing law (i.e., with another first principle) that covers all phenomena of design occurrence and evolution. This addition to physics is the Constructal law" [31]. The Constructal law states that "for a finite-size flow system to persist in time (to live), its configuration must evolve in such a way that provides greater and greater access to the currents that flow through it" [33]. "The Constructal law accounts for the universal phenomenon of generation and evolution of design (configuration, shape structure, pattern, rhythm)." This applies to "animate, inanimate and human systems" [26]. Flow being the movement of one entity relative to another is defined by what it carries (fluid, heat, mass, electricity, stress, etc.), how much it carries (flow rate, current, etc.), and where the stream is located (i.e., how it is configured). The "where" i.e., the configuration in space and time, is the focus of the constructal theories that stem from the constructal law [34-36]. Unlike conventional optimization methods wherein there are predefined existing arrangements from which the one that best satisfies the design objective is selected, application of the constructal law does not need presumptions for a configuration but builds the missing geometry from its principles. Thus, the constructal law allows the design to morph freely into ones that offer all its currents greater access to flow (i.e., better designs). The constructal law field has been 
swiftly growing in the fields of biology [24], social sciences, technology [31], and engineering [37]. It has seen its application in mechanical structures [22], porous structures [38], thermal structures [39-41], physics of life [42], power distribution systems [31, 43, 44], product design [45-47], human dynamics, security, and sustainability [48, 49]. When used to explain the evolution of airplanes, the constructal law demonstrated that airplanes must conform to the "theoretical allometric rules that unite them with the birds and other animals. For example, larger airplanes are faster, more efficient as vehicles, and have greater range. The engine mass is proportional to the body size: this scaling is analogous to animal design, where the mass of the motive organs (muscle, heart, lung) is proportional to the body size. Large or small, airplanes exhibit a proportionality between wing span and fuselage length, and between fuel load and body size. The animal-design counterparts of these features are evident" [50].

\subsection{Previous Work}

In designing flying wing aircraft, the choices of design manipulation of the structure is fairly limited when compared to conventional aircraft. Since there is basically no fuselage, two of the most commonly manipulated parameters are the wings and the placement of the engines. Mardanpour et. al [51] studied the effects of engine placement on the aeroelastic flight envelope of an aircraft. They used a constructal design of the aircraft to examine the flow of stresses and its aeroelastic stability. Their findings revealed that when the stresses in the wings are able to flow smoothly, the stability of the airplane improves. Conversely, when the location of the engine caused stress strangulation, the flutter speed significantly decreased. The location of the engine on the wing that facilitated the smoothest flow of stresses was at 80 percent span forward of the reference line. This position also resulted in the maximum flutter speed. 


\section{THEORY}

\subsection{Aeroelastic Theory}

\subsubsection{Structural Theory: Nonlinear Composite Beam Theory}

Hodges' beam theory is a fully intrinsic nonlinear composite beam theory created from first-order partial differential equations of motion that are independent of displacement and rotation variables [30]. Variables in these equations are expressed using the bases of the reference frames for the deformed $\mathrm{B}\left(x_{1}\right)$, and undeformed $\mathrm{b}\left(x_{1}, \mathrm{t}\right)$ beams seen in Fig.2 [52]. These equations of motion include angular velocity, moment, velocity with nonlinearities of second order and force which are stated as:

$$
\begin{gathered}
F_{B}^{\prime}+\widetilde{K}_{B} F_{B}+f_{B}=\dot{P}_{B}+\widetilde{\Omega}_{B} P_{B} \\
M_{B}^{\prime}+\widetilde{K}_{B} M_{B}+\left(\widetilde{e}_{1}+\widetilde{\gamma}\right) F_{B}+m_{B}=\dot{H}_{B}+\widetilde{\Omega}_{B} H_{B}+\widetilde{V}_{B} P_{B}
\end{gathered}
$$

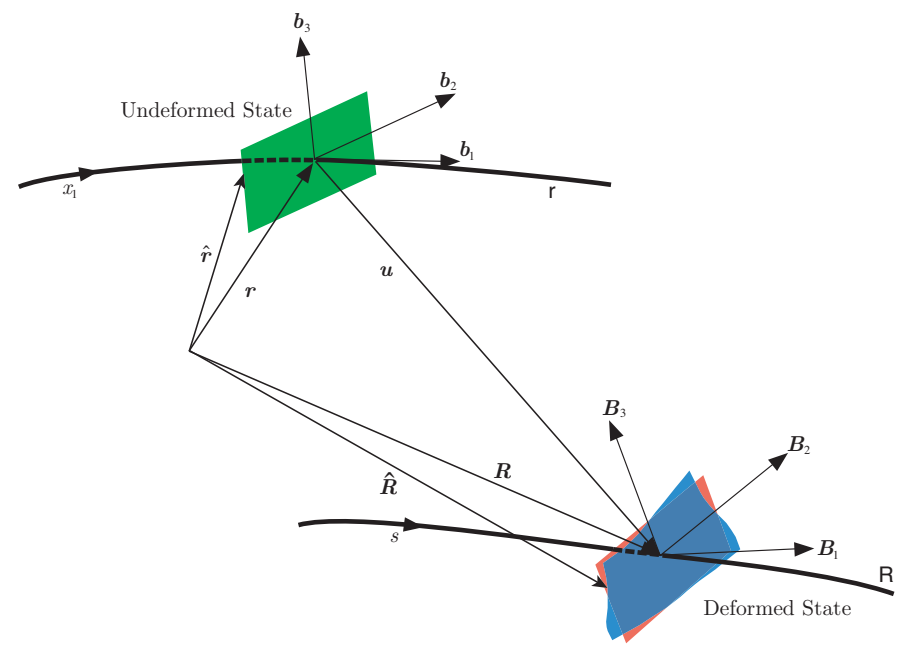

Fig. 2: The essential features of beam kinematics.

Herein, the generalized velocities and strains are related to stress resultants using the structural constitutive equations:

$$
\left\{\begin{array}{l}
\gamma \\
\kappa
\end{array}\right\}=\left[\begin{array}{ll}
R & S \\
S^{T} & T
\end{array}\right]\left\{\begin{array}{l}
F_{B} \\
M_{B}
\end{array}\right\}
$$


and the inertial constitutive equations:

$$
\left\{\begin{array}{c}
P_{B} \\
H_{B}
\end{array}\right\}=\left[\begin{array}{cc}
\mu \Delta & -\mu \widetilde{\xi} \\
\mu \widetilde{\xi} & I
\end{array}\right]\left\{\begin{array}{l}
V_{B} \\
\Omega_{B}
\end{array}\right\} .
$$

The strain- and velocity- displacement equations are used to derive the geometrically exact intrinsic kinematical partial differential equations [30] that do not contain nonlinearities of third and higher degrees which are given as:

$$
\begin{aligned}
V_{B}^{\prime}+\widetilde{K}_{B} V_{B}+\left(\widetilde{e}_{1}+\widetilde{\gamma}\right) \Omega_{B} & =\dot{\gamma} \\
\Omega_{B}^{\prime}+\widetilde{K}_{B} \Omega_{B} & =\dot{\kappa}
\end{aligned}
$$

For these sets of equations:

$F_{B}$ and $M_{B}$ are column vectors of cross-sectional stress and moment resultant measures in the $B$ frame, respectively;

$V_{B}$ and $\Omega_{B}$ are column vectors of cross-sectional frame velocity and angular velocity measures in the $B$ frame, respectively;

$P_{B}$ and $H_{B}$ are column vectors of cross-sectional linear and angular momentum measures in the $B$ frame, respectively;

$R, S$, and $T$ are $3 \times 3$ partitions of the cross-sectional flexibility matrix;

$\Delta$ is the $3 \times 3$ identity matrix;

$I$ is the $3 \times 3$ cross-sectional inertia matrix;

$\xi$ is $\left\lfloor\begin{array}{lll}0 & \xi_{2} & \xi_{3}\end{array}\right\rfloor^{T}$ with $\xi_{2}$ and $\xi_{3}$ representing the position coordinates of the cross-sectional mass center with respect to the reference line;

$\mu$ is the mass per unit length;

$\widetilde{(~)}$ denotes the anti-symmetric $3 \times 3$ matrix associated with the column vector over which the tilde is placed;

( ) denotes the partial derivative with respect to time; 
()$^{\prime}$ denotes the partial derivative with respect to the axial coordinate, $x_{1}$.

Reference [53] gives more details on these equations. If desired, the position and the orientation can be calculated as post-processing operations by integrating:

$$
\begin{gathered}
r_{i}^{\prime}=C^{i b} e_{1} \\
r_{i}+u_{i}^{\prime}=C^{i B}\left(e_{1}+\gamma\right)
\end{gathered}
$$

and

$$
\begin{aligned}
\left(C^{b i}\right)^{\prime} & =-\widetilde{k} C^{b i} \\
\left(C^{B i}\right)^{\prime} & =-(\widetilde{k}+\widetilde{\kappa}) C^{B i}
\end{aligned}
$$

Here $C$ defines the transformation matrix, $r$ is the column vector of position vector measured in $\mathbf{b}_{i}$ basis, and $u$ indicates the column vector of displacement vector measured in $\mathbf{b}_{i}$ basis.

\subsubsection{Aerodynamic Theory: 2D Induced Flow Theory of Peters}

Peters et al. [54] present a two-dimensional aerodynamic model that is a state-space, thin airfoil, inviscid, incompressible approximation of an infinite-state representation of the aerodynamic loads that is also used by NATASHA. Using known airfoil parameters, these loads are responsible for the induced flow in the wake and apparent mass effects. The aerodynamic model accommodates deflection of a small trailing-edge flap as well as large motion of the airfoil. The two-dimensional version of this model does not account for three dimensional effects associated with the wing tip [54-56] but demonstrates that this theory is a great approximation of aerodynamic loads acting on high-aspect ratio wings. The lift, drag and pitching moment at the quarter-chord are given by:

$$
\begin{gathered}
L_{\text {aero }}=\rho b\left[\left(c_{l_{0}}+c_{l_{\beta}} \beta\right) V_{T} V_{a_{2}}-c_{l_{\alpha}} \dot{V}_{a_{3}} b / 2-c_{l_{\alpha}} V_{a_{2}}\left(V_{a_{3}}+\lambda_{0}-\Omega_{a_{1}} b / 2\right)-c_{d_{o}} V_{T} V_{a_{3}}\right] \\
D_{\text {aero }}=\rho b\left[-\left(c_{l_{0}}+c_{l_{\beta}} \beta\right) V_{T} V_{a_{3}}+c_{l_{\alpha}}\left(V_{a_{3}}+\lambda_{0}\right)^{2}-c_{d_{o}} V_{T} V_{a_{2}}\right]
\end{gathered}
$$


$M_{\text {aero }}=2 \rho b\left[\left(c_{m_{0}}+c_{m_{\beta}} \beta\right) V_{T}-c_{m_{\alpha}} V_{T} V_{a_{3}}-b c_{l_{\alpha}} / 8 V_{a_{2}} \Omega_{a_{1}}-b^{2} c_{l_{\alpha}} \dot{\Omega}_{a_{1}} / 32+b c_{l_{\alpha}} \dot{V}_{a_{3}} / 8\right]$

where

$$
\begin{gathered}
V_{T}=\sqrt{V_{a_{2}}^{2}+V_{a_{3}}^{2}} . \\
\sin \alpha=\frac{-V_{a_{3}}}{V_{T}} \\
\alpha_{r o t}=\frac{\Omega_{a_{1}} b / 2}{V_{T}}
\end{gathered}
$$

and $V_{a_{2}}, V_{a_{3}}$ are the measured values of $V_{a}$, and $\beta$ is the angle of flap deflection. The effect of unsteady wake (induced flow) and apparent mass appear as $\lambda_{0}$ and acceleration terms in the force and moment equations. The induced flow model of Peters et al. [54] is included to calculate $\lambda_{0}$ as,

$$
\lambda_{0}=\frac{1}{2}\left\{b_{\text {induced flow }}\right\}^{T}\{\lambda\}
$$

where $\lambda$ is the column vector of induced flow states, and $\left[A_{\text {induced }}\right.$ flow $]$, is a constant matrix derived in Ref.[54].

\subsection{NATASHA}

Nonlinear Aeroelastic Trim And Stability of HALE Aircraft (NATASHA) was used to assess the aeroelastic behavior of a flying wing aircraft with inflected wings. Being fundamentally based on Hodges' nonlinear composite beam theory, NATASHA can evaluate the dynamic behavior of a general, anisotropic, nonuniform beam that experiences a large deformation. For calculations, singularities due to finite rotations are avoided and equations of motion are independent of displacement and rotation variables. This system of nonlinear equations of motion is solved numerically and the state variables are based on forces, moments, angular velocities, and linear velocities. This system of nonlinear equations, when 
linearized about the resulting trim state (i.e., equilibrium state), leads to a standard eigenvalue problem, which is used to analyze the stability of the structure. Mardanpour et al. have used NATASHA in studies such as the effects of engine placement on the nonlinear aeroelastic trim and stability as well gust suppression for a flexible wing [20, 57-61].

NATASHA $[62,63]$ is a powerful code for determining the aeroelastic behavior of HALE aircraft. The aeroelastic system is a description of the coupling of the aerodynamic and structural equations:

$$
[A]\{\dot{x}\}+\{B(x)\}=\left\{f_{\text {cont }}\right\}
$$

where, $\{x\}$ and $f_{\text {cont }}$ represent the vector of all the aeroelastic variables and the vector of the flight controls, respectively. The resulting nonlinear ordinary differential equations are linearized about a static equilibrium state. The equilibrium state is governed by nonlinear algebraic equations, which the code NATASHA solves in obtaining the steady-state trim solution using the Newton-Raphson procedure [62]. This system of nonlinear aeroelastic equations, when linearized about the resulting trim state, leads to a standard eigenvalue problem, which NATASHA uses to analyze the stability of the structure. The linearized system can be represented as:

$$
[A]\{\dot{\hat{x}}\}+[B]\{\hat{x}\}=\left\{\hat{f}_{\text {cont }}\right\}
$$

where $(\hat{)}$ indicates the perturbation about the steady-state values. The trim equations are available in the work by Patil et al. [62]. They mentioned that the trim conditions are the same as steady-state conditions, in which all the time-derivatives are zero. The symmetric trim equations are:

$$
\hat{g}_{2} \hat{V}_{2}+\hat{g}_{3} \hat{V}_{3}-\tan \phi\left(\hat{g}_{3} \hat{V}_{2}-\hat{g}_{2} \hat{V}_{3}\right)=0
$$




$$
\hat{V}_{2}^{2}+\hat{V}_{3}^{2}-\hat{V}_{\infty}^{2}=0
$$

where $\phi$ and $V_{\infty}$ are the prescribed flight angle and airspeed, respectively.

NATASHA has been verified and validated [55], applied to the study of the effects of sweep on the flutter and divergence [20], and its results tested against the classical cantilever wing model of Goland and Luke [56]. References [60, 61, 64, 65] present more information on the systems of equations and the methods of solutions that NATASHA uses. 


\section{METHODOLOGY}

To generate each model, the sectional geometry of the fuselage and the wings are created in Gmsh. The structural properties of each model are then obtained in VABS ${ }^{\mathrm{TM}}$. These properties are imported into NATASHA for stability analysis. NATASHA produces the trim state solutions which are imported back to $\mathrm{VABS}^{\mathrm{TM}}$ for stress recovery.

\subsection{Software}

\subsubsection{Gmsh}

Gmsh is an open-source 3D finite element mesh generator with integrated CAD engine and post-processor. It supplies a quick, light and user friendly meshing tool with parametric input and advanced visualization capabilities. Gmsh consists of four components : geometry, mesh, solver and post-processing [66].

\subsubsection{Variational Asymptotic Beam Sectional Analysis (VABS ${ }^{\mathrm{TM}}$ )}

The cross sectional properties of the high-aspect ratio wing were obtained using VABS ${ }^{\mathrm{TM}}$ [67-69]. VABS ${ }^{\mathrm{TM}}$ is a commercial software that is specially designed to compute the sectional properties of slender composite bodies as well as recovering its $3 \mathrm{D}$ properties. It does this using the variational method to make the 3D slender solid into a simple engineering beam model. This reduced the analysis time significantly while producing results with high accuracy. VABS ${ }^{\mathrm{TM}}$ calculates the sectional properties of a beam such as the structural and inertial properties using the finite element mesh of the cross section of the geometry that is given by the user. It also has the capability to conduct stress recovery using the inputs of forces and moments.

\subsubsection{NATASHA}

Nonlinear Aeroelastic Trim And Stability of HALE Aircraft (NATASHA), explained indept in Chapter 3.2, was used to assess the aeroelastic behavior of a flying wing aircraft with 
inflected wings. NATASHA uses a standard eigenvalue problem to analyze the stability of the structure.

\subsection{Stress Recovery Procedure}

The sectional geometry, mesh, and material property of the fuselage and the wings for each flying wing aircraft model are created in Gmsh and its structural and elemental properties obtained from VABS ${ }^{\mathrm{TM}}$. For the corrected cross-sectional properties, it should be ensured that the curvature of each geometry or element is inputted into VABS ${ }^{\mathrm{TM}}$ since the initial twist and curvature of the geometry introduces some elastic couplings [70]. These elemental and structural properties are imported into NATASHA in order to perform a stability analysis. The trim state solutions from NATASHA are re-imported into VABS ${ }^{\text {TM }}$ to obtain the stresses throughout the structure (stress recovery). These stresses are captured and displayed in a post-processing program written in MATLAB. Figure 3 shows the process of design and analysis for the study.

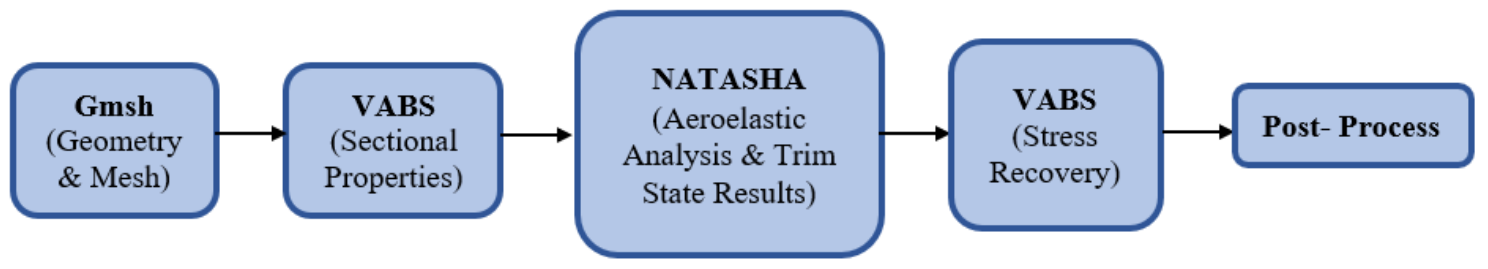

Fig. 3: Design generation and analysis process.

\subsection{Case Study}

The flow of stresses and the aeroelastic stability of a flying wing aircraft without inflection are compared with those of flying wing aircraft configurations that have inflected wings. Figure 4 and Figure 5 present 3D views of the models of the flying wing aircraft without inflection and with inflection respectively. Table 1 displays the properties of the flying wing aircraft configuration without inflection. It should be noted that the wing span, 
chord, and sweep angle are the same for all configurations (inflected and without inflection). The flexibility components of a geometry with curvature and an isotropic material are slightly different from the one without curvature as explained by Yu et al. [70]. All other properties in the table are obtained from $\mathrm{VABS}^{\mathrm{TM}}$. Table 2 shows the flap-wise curvature (inflection) given to the different test cases.

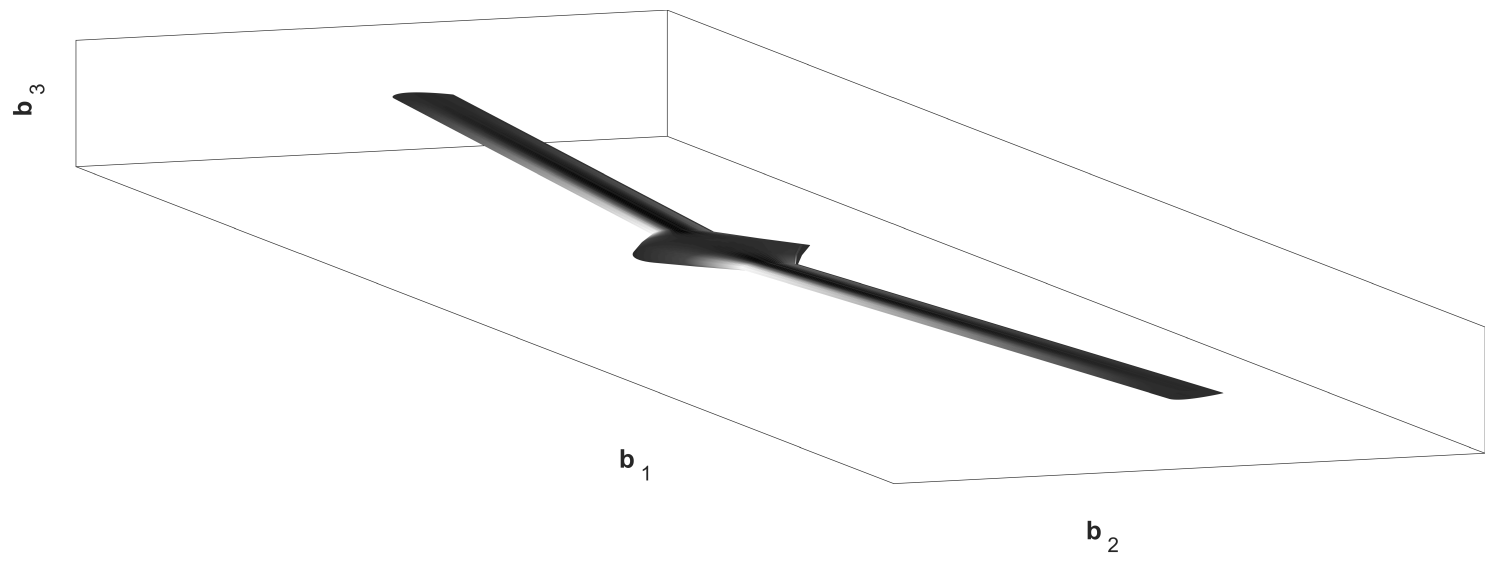

Fig. 4: Schematic view of flying wing aircraft without curvature.

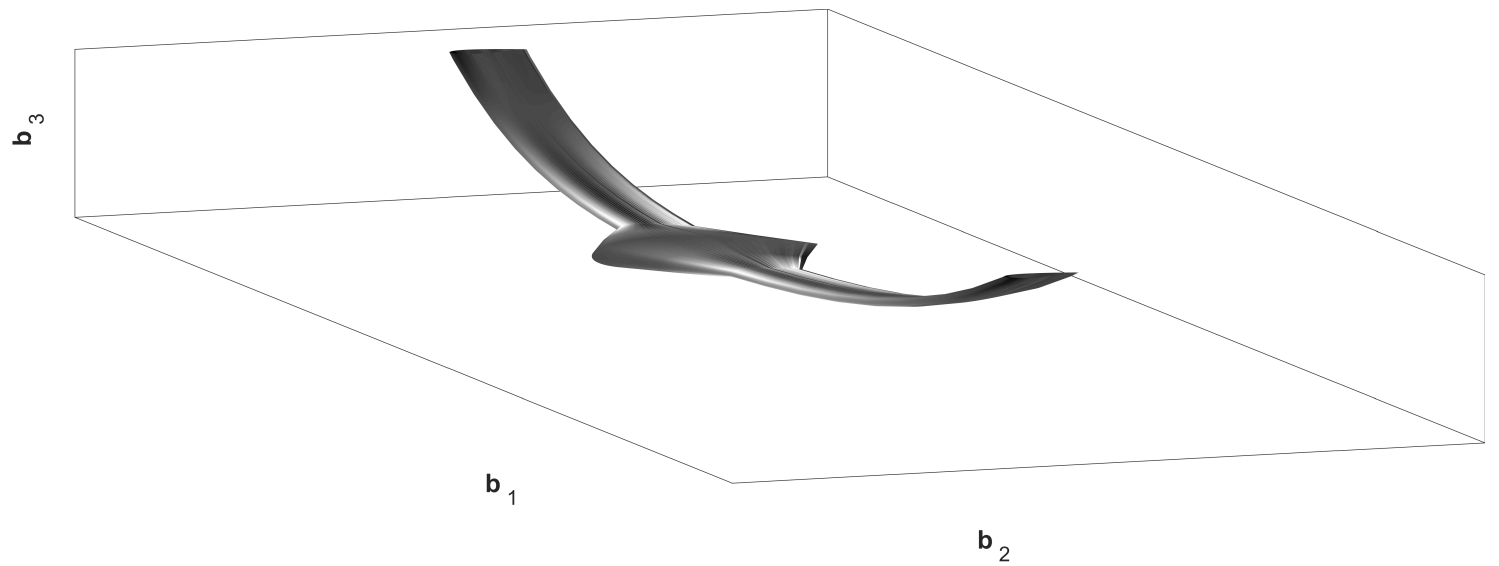

Fig. 5: Schematic view of inflected flying wing aircraft. 
Table 1: Properties of the flying wing aircraft configuration without inflection

\begin{tabular}{|c|c|c|c|}
\hline Span & \multicolumn{3}{|c|}{$18 \mathrm{~m}$} \\
\hline Chord & \multicolumn{3}{|c|}{$\frac{1 \mathrm{~m}}{5^{\circ}}$} \\
\hline Sweep Angle & & $5^{\circ}$ & \\
\hline$\xi[m]$ & & {$\left[\begin{array}{c}0 \\
1.13 e^{-} 01 \\
1.25 e^{-} 17\end{array}\right]$} & \\
\hline I[kg.m] & {$\left[\begin{array}{c}1.56 e^{-} 01 \\
0 \\
0\end{array}\right.$} & $\begin{array}{c}0 \\
2.34 e^{-} 03 \\
-1.69 e^{-} 18\end{array}$ & $\left.\begin{array}{c}0 \\
-1.69 e-18 \\
1.54 e^{-} 01\end{array}\right]$ \\
\hline$T\left[N^{-} 1 m^{-} 2\right]$ & {$\left[\begin{array}{c}3.48 e-06 \\
0 \\
0\end{array}\right.$} & $\begin{array}{c}0 \\
4.27 e^{-} 06 \\
-6.66 e^{-} 14\end{array}$ & $\left.\begin{array}{c}0 \\
-6.66 e^{-} 14 \\
6.51 e^{-8}\end{array}\right]$ \\
\hline$R\left[N^{-} 1\right]$ & {$\left[\begin{array}{c}7.24 e-0 s \\
0 \\
0\end{array}\right.$} & $\begin{array}{c}0 \\
2.58 e-08 \\
1.75 e-13\end{array}$ & $\left.\begin{array}{c}0 \\
1.76 e-13 \\
9.66 e-07\end{array}\right]$ \\
\hline$S\left[N^{-} 1 m^{-} 1\right]$ & {$\left[\begin{array}{c}0 \\
-3.34 e-14 \\
-1.16 e-06\end{array}\right.$} & $\begin{array}{c}-7.55 e-15 \\
0 \\
4\end{array}$ & $\left.\begin{array}{cc}5 & 7.37 e-09 \\
0 \\
0\end{array}\right]$ \\
\hline
\end{tabular}

Table 2: Flap-wise curvature (rad) for the different test cases

\begin{tabular}{ccc}
\hline \hline Case Number & Curvature at Root & Curvature at Tip \\
\hline \hline 1 & 0.00 & 0.00 \\
\hline 2 & 0.02 & -0.04 \\
\hline 3 & 0.03 & -0.06 \\
\hline 4 & 0.07 & -0.18 \\
\hline 5 & 0.05 & -0.14 \\
\hline 6 & 0.05 & -0.15 \\
\hline 7 & 0.10 & -0.20 \\
\hline 8 & 0.09 & -0.18 \\
\hline
\end{tabular}




\section{RESULTS AND DISCUSSION}

Presented in this section are the findings from the flutter and stress analyses for the flying wing aircraft without inflection and the other configurations with inflection.

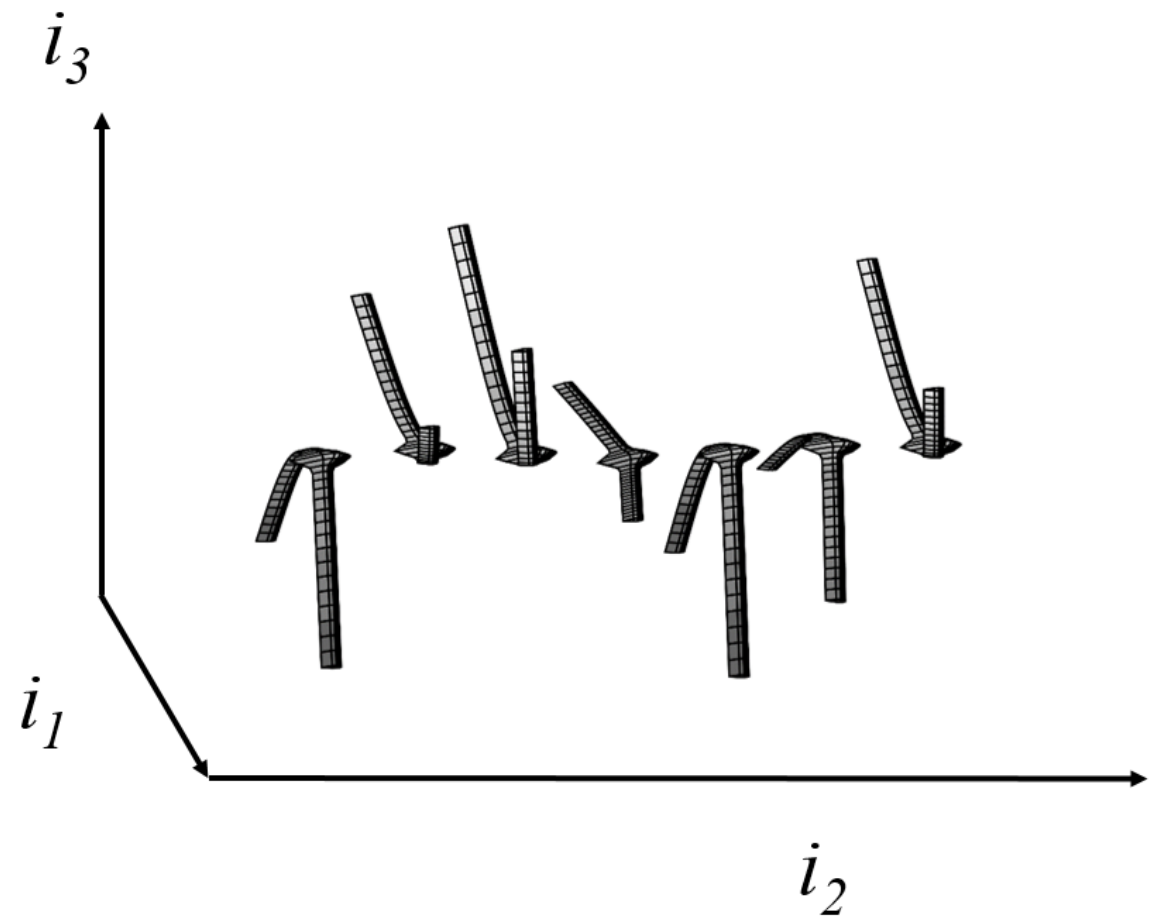

Fig. 6: The unstable symmetric free-free mode shape of the base model flying wing.

Figure 6 shows the body-freedom flutter mode of the airplane model without inflection. This aircraft has only first bending mode.

One of the greatest advantages of NATASHA is that it uses the p-method for analysis which accounts for the "margin of stability at flight conditions in the vicinity of the flutter boundary" and provides insight into the "physical mechanisms that cause the instability" [14]. Hence its result yields $n+1$ conjugate pairs. At a certain speed during the iterative process, one hundred eigenvalues are obtained. A plot of these eigenvalues wherein the speed is normalized with its flutter speed and the eigenvalues (real and imaginary) normalized with its flutter frequency for the base model flying wing is shown in Fig. 7. In Fig. 7 (a.), the curve seen that moves from the negative real part of the eigenvalues to positive val- 
ues depicts an instability. When this curve crosses other curves at positive real eigenvalues, the point of intersection is where flutter occurs. Curves that only have negative eigenvalues imply stability of the structure whereas those consistently having positive real eigenvalues indicate that there is divergence.

Table 3 shows the speeds at which configurations that had inflected wings or no curvature fluttered. From the results, the aircraft with no inflection had the lowest flutter speed i.e., adding curvature in the flap- wise direction (inflection) increased the speed at which the aircraft fluttered.

Table 3: Flutter speed for different curvatures

\begin{tabular}{cc}
\hline \hline Case Number & Flutter Speed $(\mathrm{m} / \mathrm{s})$ \\
\hline \hline 1 & 37.3 \\
\hline 2 & 41.1 \\
\hline 3 & 46.4 \\
\hline 4 & 68.2 \\
\hline 5 & 78.9 \\
\hline 6 & 86.3 \\
\hline 7 & 91.7 \\
\hline 8 & $>100$ \\
\hline
\end{tabular}

As explained in Chapter 4, VABS ${ }^{\mathrm{TM}}$ is used for the stress analysis for the flying wing airplanes at a cruise speed of $35 \mathrm{~m} / \mathrm{s}$. This is achieved by using the trim state results from NATASHA as input to VABS ${ }^{\mathrm{TM}}$. All of the results for the stress distribution are plotted and the most relevant ones are presented in Figs. 8- 11. For the stress distributions, the airfoil shown is located at the root of the wing where the largest concentration of stresses is expected to occur.

Figure 8 displays the stress distribution for $\sigma_{11}$ for the full aircraft and the airfoil. As is shown, the case without curvature is experiencing compression at the upper surface and has a high concentration of stress at the roots of the wings. Addition of curvature to the structure, starting with Case 2, begins to distribute the stresses towards the wing tips (seen by a lower 


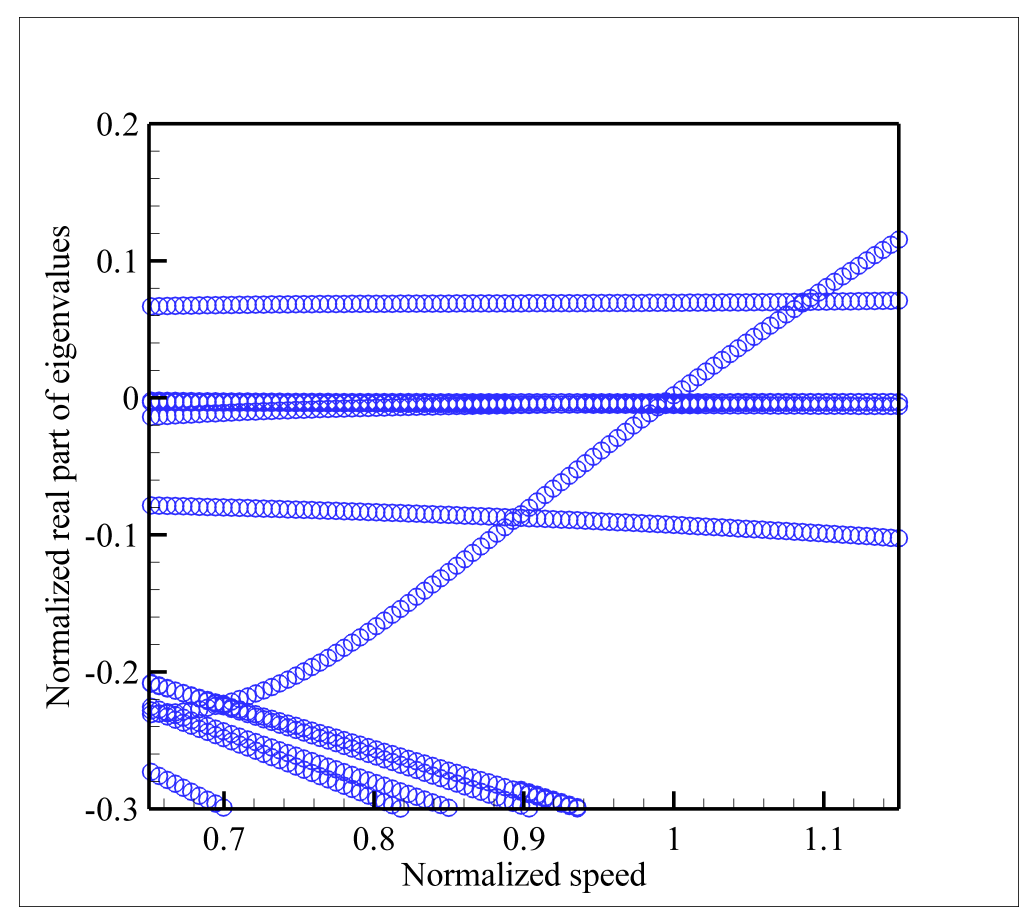

(a.)

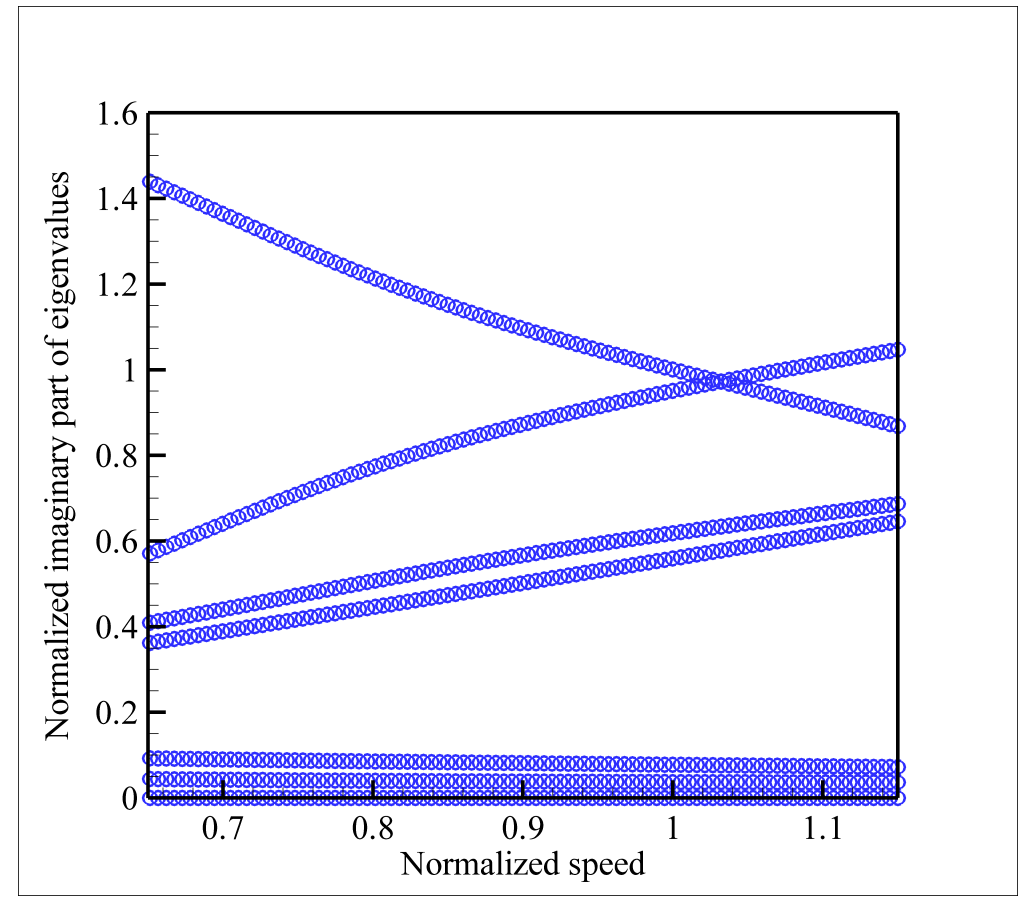

(b.)

Fig. 7: Eigenvalue analysis of base model flying wing. 
magnitude of stress at a given point). In essence, the addition of inflection causes the flutter speed to increase. This increase is as a result of the structure being able to accommodate the flow of stresses "better" through the avoidance of flow strangulation. The stress plots for $\sigma_{11}$ are comparable to those of Von Mises in Fig. 11 since they have the highest order of magnitude of $2 \times 10^{6} \mathrm{~Pa}$ among all the plots.

Figure 9 and Figure 10 display the stress distribution for $\sigma_{12}$ and $\sigma_{13}$ respectively. The range of the magnitude of the stresses for $\sigma_{12}$ is $-1.0 \times 10^{5}$ to $1.0 \times 10^{5} \mathrm{~Pa}$ and zero to $2.0 \times 10^{4}$ Pa for $\sigma_{13}$. Since these are not the dominant stresses, these results are presented just to show their behaviour. An analysis of the $\sigma_{12}$ stress distribution tells that as curvature is added to the wing the stress concentration is not necessarily improving and flow strangulation occurs. The same phenomenon is true for the case of $\sigma_{13}$.

Finally, Fig. 11 displays the Von Mises stresses. Case 1 shows stress strangulation at the root of the wing and as curvature is added to the structure, this strangulation starts to "smooth out" to almost zero. 


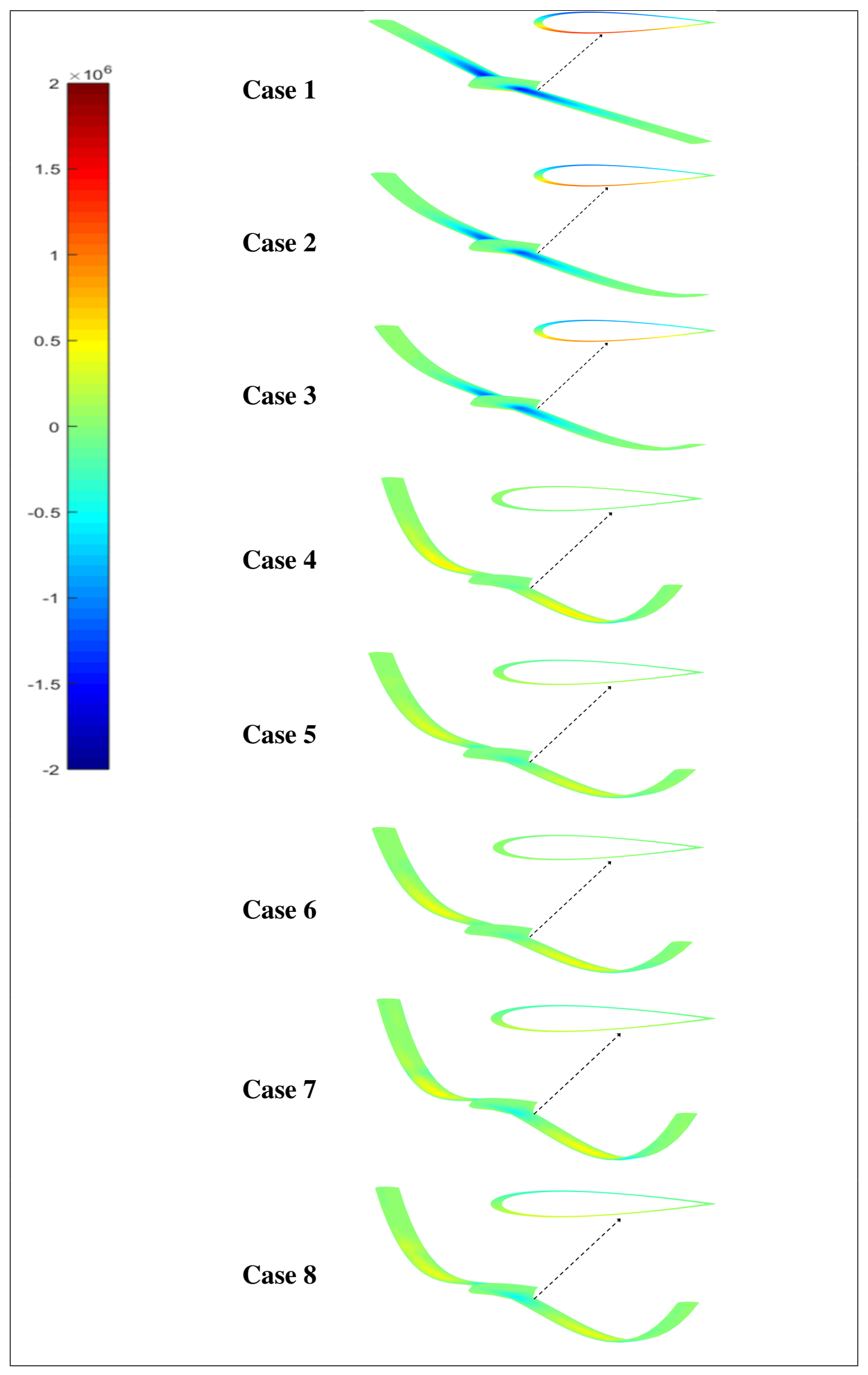

Fig. 8: Stress distribution for the flying wing, $\sigma_{11}(\mathrm{~Pa})$. 


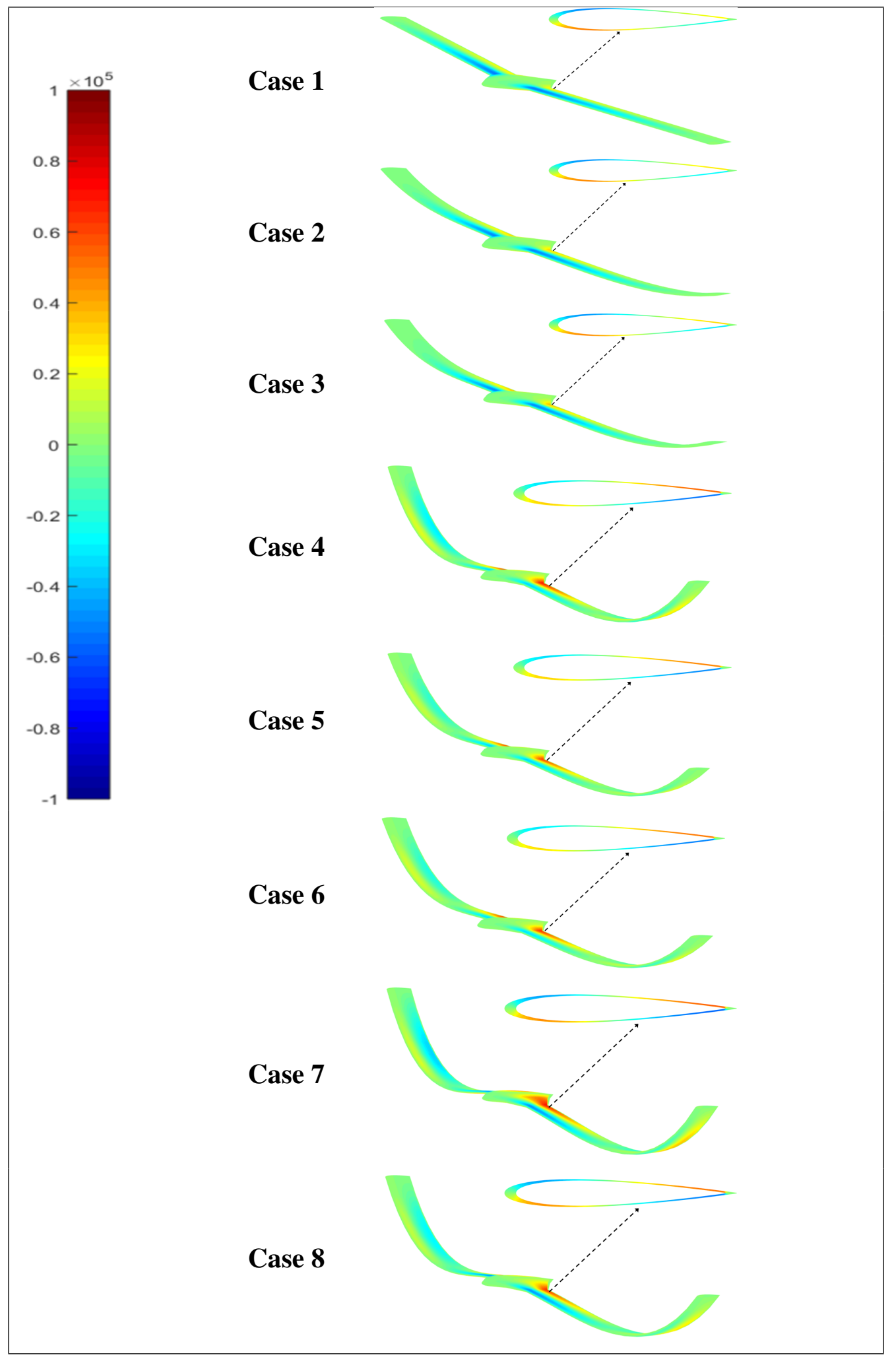

Fig. 9: Stress distribution for the flying wing, $\sigma_{12}(\mathrm{~Pa})$. 


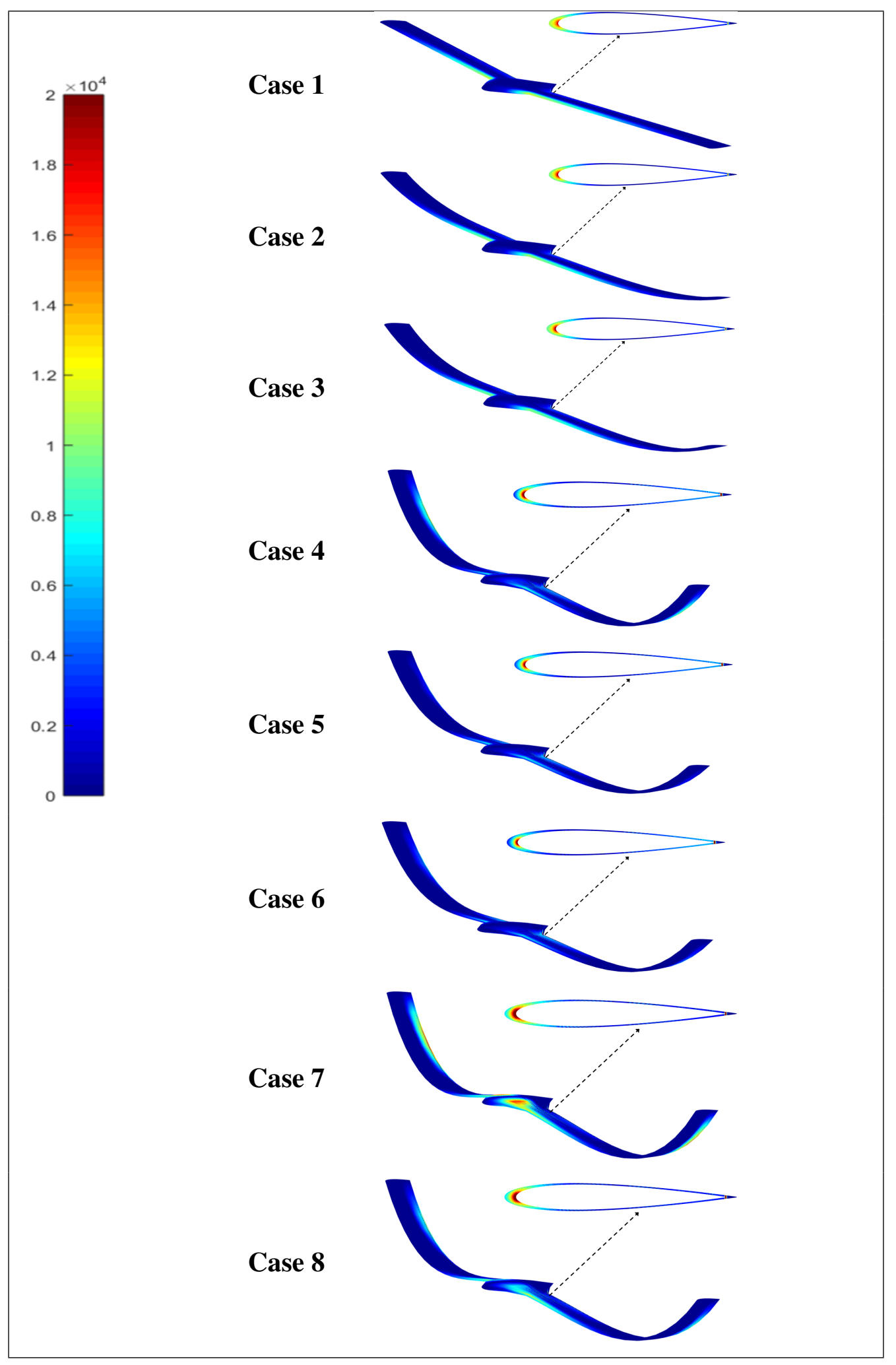

Fig. 10: Stress distribution for the flying wing, $\sigma_{13}(\mathrm{~Pa})$. 


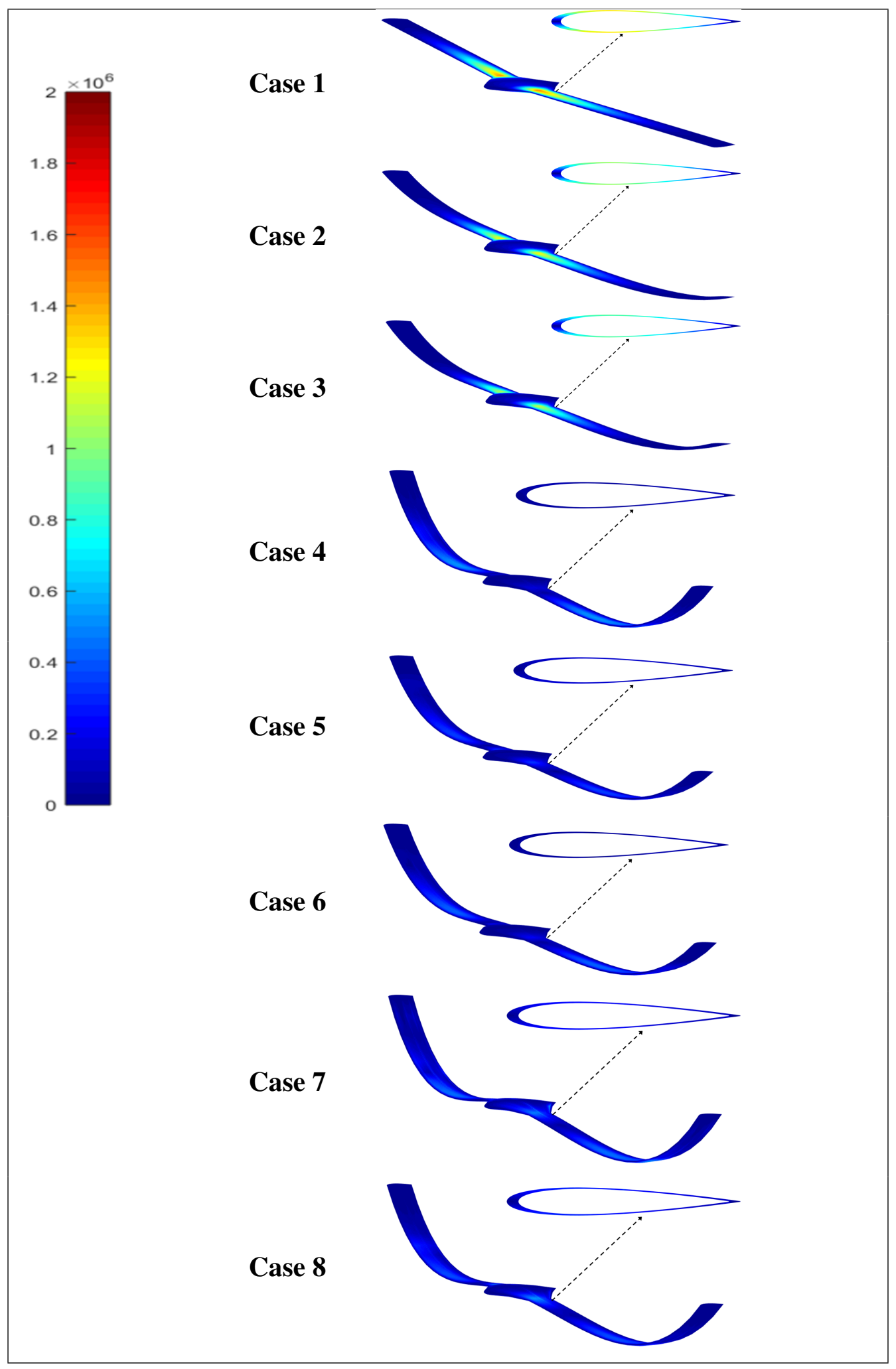

Fig. 11: Stress distribution for the flying wing, Von Mises (Pa). 


\section{CONCLUSION}

In order to solve the problem of aeroelastic instability in HALE aircraft, Hodges et. al [14] explains that there are two very important considerations to be made. "The first is to obtain an understanding of the margin of stability at flight conditions in the vicinity of the flutter boundary. The second and possibly the more important, is to obtain an understanding of the physical mechanism that causes the instability." NATASHA has demonstrated its capability of providing solutions to these considerations through its capturing of the flutter conditions of the flying wing airplanes studied. Further insight in the physical mechanisms that causes the instabilities was provided by the implementation of the concept of the flow of stresses. Recently introduced by Lorente et al. [22], this concept suggests that a structure that is the lightest and that can tolerate larger forces is the one that will facilitate the flow of stresses and avoid flow strangulation. Explained using the constructal law, the flow of stresses in a solid body that allows the flow to morph freely so that it provides a greater access to its currents (in this case the stresses), avoids flow strangulation. In this research, the constructal law dictated the design of a flying wing airplane that increases the flutter speed by avoiding flow strangulations (i.e., stress concentration). It is a design that has inflected wings.

For this study, a flying wing aircraft without inflection and seven others with inflected wings, having different degrees of curvature, are studied. All designs are flexible and lightweight structures with the same wing span, chord and fuselage dimensions. Gmsh, VABS ${ }^{\mathrm{TM}}$ and NATASHA are the software programs used throughout the study for aeroelastic and stress analyses. From the results of the stability analyses, the wing without curvature has the lowest flutter speed. While adding curvature increases the flutter speed substantially, a comparison of the different components of the stress matrix shows that $\sigma_{11}$ and Von Mises have the largest magnitudes so they are the dominant stresses. Their distributions reveal that there is a relation between the flow of this component of stress and instability. Using a constructal approach to explain this phenomenon, the wing structure that accommodates 
the flow of stresses more easily (measured by the stress distribution), is the one that avoids flow strangulation and ultimately have the highest flutter speed.

The constructal law has been a necessary physics principle for the explanation of many designs such as the one design for animals, government structure, and technology. This first principle has also lent itself to the design of inflected airplane wings in this research. Expanding its application in designs with inflection, the design of turbine blades will be studied in future. An expansion on this research could also be the study of flying wing aircraft with curvature in the direction of sweep. 


\section{REFERENCES}

[1] S Powell, E Izadpanahi, S Rastkar, and P Mardanpour. Constructal approach to the design of inflected airplane wings. In AIAA Scitech 2019 Forum, page 0226, 2019.

[2] CP Van Dam. Induced-drag characteristics of crescent-moon-shaped wings. Journal of Aircraft, 24(2):115-119, 1987.

[3] D Lentink, UK Müller, EJ Stamhuis, R De Kat, W Van Gestel, LLM Veldhuis, Per Henningsson, Anders Hedenström, John J Videler, and Johan L Van Leeuwen. How swifts control their glide performance with morphing wings. Nature, 446(7139):1082, 2007.

[4] A Wickenheiser and E Garcia. Aerodynamic modeling of morphing wings using an extended lifting-line analysis. Journal of Aircraft, 44(1):10-16, 2007.

[5] M R Chiarelli, M Cagnoni, M Ciabattari, M De Biasio, and A Massai. Preliminary analysis of a high aspect ratio wing with curved planform. AIDAA 2009, MILAN, Italy, 2009.

[6] MR Chiarelli, M Cagnoni, M Ciabattari, M De Biasio, and A Massai. High aspect ratio wing with curved planform: Cfd and fe analyses. ICAS 2010, NICE, France, 2010.

[7] AYN Sofla, SA Meguid, KT Tan, and WK Yeo. Shape morphing of aircraft wing: Status and challenges. Materials \& Design, 31(3):1284-1292, 2010.

[8] MR Chiarelli, G Lombardi, and A Nibio. A straight wing and a forward swept wing compared with a curved planform wing in the transonic regime. CEAS 2011, VENICE, Italy, 2011.

[9] VP Galantai, AYN Sofla, SA Meguid, KT Tan, and WK Yeo. Bio-inspired wing morphing for unmanned aerial vehicles using intelligent materials. International Journal of Mechanics and Materials in Design, 8(1):71-79, 2012.

[10] N Nguyen, K Trinh, K Reynolds, J Kless, M Aftosmis, and J Urnes. Elastically shaped wing optimization and aircraft concept for improved cruise efficiency. In 51st AIAA Aerospace Sciences Meeting Including the New Horizons Forum and Aerospace Exposition, page 141, 2013.

[11] A Benaouali and Sław Kachel. Parametric design of aircraft wing with curved leading edge. Problemy Mechatroniki: uzbrojenie, lotnictwo, inżynieria bezpieczeństwa, 9, 2018.

[12] M Manikanta Dora. International journal of research an investigation on naca 2312 aerofoil with curved and straight leading edge wing. 042018.

[13] Md M I Khan and A Al-Faruk. Comparative analysis of aerodynamic characteristics of rectangular and curved leading edge wing planforms. American Journal of Engineering Research, 2018. 
[14] D H Hodges and G A Pierce. Introduction to structural dynamics and aeroelasticity, volume 15. cambridge university press, 2011.

[15] R L Bisplinghoff, H Ashley, and R L Halfman. Aeroelasticity. Courier Corporation, 2013.

[16] G Hodges. Active flutter suppression-b-52 controls configured vehicle. In Dynamics Specialists Conference, page 322, 1973.

[17] SA Fazelzadeh, A Mazidi, AR Rahmati, and P Marzocca. The effect of multiple stores arrangement on flutter speed of a shear deformable wing subjected to pull-up angular velocity. The Aeronautical Journal, 113(1148):661-668, 2009.

[18] SA Fazelzadeh, P Marzocca, E Rashidi, and A Mazidi. Effects of rolling maneuver on divergence and flutter of aircraft wing store. Journal of Aircraft, 47(1):64-70, 2010.

[19] A Mazidi, H Kalantari, and SA Fazelzadeh. Aeroelastic response of an aircraft wing with mounted engine subjected to time-dependent thrust. Journal of Fluids and Structures, 39:292-305, 2013.

[20] P Mardanpour, D H Hodges, R Neuhart, and N Graybeal. Engine placement effect on nonlinear trim and stability of flying wing aircraft. Journal of Aircraft, 50(6):17161725, 2013.

[21] P Mardanpour, P W Richards, O Nabipour, and D H Hodges. Effect of multiple engine placement on aeroelastic trim and stability of flying wing aircraft. Journal of Fluids and Structures, 44:67-86, 2014.

[22] S Lorente, J Lee, and A Bejan. The "flow of stresses" concept: the analogy between mechanical strength and heat convection. International Journal of Heat and Mass Transfer, 53(15-16):2963-2968, 2010.

[23] A Bejan and S Lorente. Constructal law of design and evolution: physics, biology, technology, and society. Journal of Applied Physics, (15):151301, 2013.

[24] A Bejan and S Lorente. The constructal law of design and evolution in nature. Philosophical Transactions of the Royal Society B: Biological Sciences, 365(1545):13351347, 2010.

[25] A Bejan and S Lorente. The constructal law and the design of the biosphere: nature and globalization. Journal of Heat Transfer, 133(1):011001, 2011.

[26] A Bejan and S Lorente. The constructal law and the evolution of design in nature. Physics of life Reviews, 8(3):209-240, 2011.

[27] L AO Rocha, S Lorente, and A Bejan. Constructal law and the unifying principle of design. Springer, 2012. 
[28] H Kobayashi, S Lorente, R Anderson, and A Bejan. Trees and serpentines in a conducting body. International Journal of Heat and Mass Transfer, 56(1-2):488-494, 2013.

[29] A Bejan. Constructal-theory network of conducting paths for cooling a heat generating volume. International Journal of Heat and Mass Transfer, 40(4):799-816, 1997.

[30] D H Hodges. Geometrically exact, intrinsic theory for dynamics of curved and twisted anisotropic beams. AIAA journal, 41(6):1131-1137, 2003.

[31] A Bejan and S Lorente. Constructal law of design and evolution: Physics, biology, technology, and society. Journal of Applied Physics, 113(15):-, 2013.

[32] A Bejan. Advanced engineering thermodynamics. John Wiley \& Sons, 2016.

[33] A Bejan and S Lorente. The constructal law of design and evolution in nature. Philosophical Transactions of the Royal Society of London B: Biological Sciences, 365(1545):1335-1347, 2010.

[34] A. Bejan and S. Lorente. The constructal law and the thermodynamics of flow systems with configuration. International Journal of Heat and Mass Transfer, 47(1416):3203-3214, 2004.

[35] A Bejan and S Lorente. Constructal theory of generation of configuration in nature and engineering. Journal of Applied Physics, 100(4), 2006.

[36] A Bejan and S Lorente. Design with constructal theory. Design with Constructal Theory, pages 1-529, 2008.

[37] A Bejan. Shape and structure, from engineering to nature. Cambridge university press, 2000.

[38] G Lorenzini, C Biserni, LA Isoldi, ED Dos Santos, and LAO Rocha. Constructal design applied to the geometric optimization of y-shaped cavities embedded in a conducting medium. Journal of Electronic Packaging, 133(4):041008, 2011.

[39] V A Prasad Raja, T Basak, and S K Das. Thermal performance of a multi-block heat exchanger designed on the basis of bejan's constructal theory. International Journal of Heat and Mass Transfer, 51(13-14):3582-3594, 2008.

[40] X Liu, L Chen, H Feng, and F Sun. Constructal design for blast furnace wall based on the entransy theory. Applied Thermal Engineering, 100:798-804, 2016.

[41] J Yang, S-R Oh, and W Liu. Optimization of shell-and-tube heat exchangers using a general design approach motivated by constructal theory. International Journal of Heat and Mass Transfer, 77:1144-1154, 2014. 
[42] A Bejan. The physics of life : the evolution of everything. St. Martins Press, New York City, 2016.

[43] A V Azad and M Amidpour. Economic optimization of shell and tube heat exchanger based on constructal theory. Energy, 36(2):1087-1096, 2011.

[44] AF Miguel. Dendritic structures for fluid flow: laminar, turbulent and constructal design. Journal of Fluids and Structures, 26(2):330-335, 2010.

[45] G Hernandez, J K Allen, and F Mistree. Platform design for customizable products as a problem of access in a geometric space. Engineering Optimization, 35(3):229-254, 2003.

[46] M J Carone, C B Williams, J K Allen, and F Mistree. An application of constructal theory in the multi-objective design of product platforms. In ASME 2003 International Design Engineering Technical Conferences and Computers and Information in Engineering Conference, pages 719-730. American Society of Mechanical Engineers, 2003.

[47] G Hernandez, J K Allen, and F Mistree. Design of hierarchic platforms for customizable products. In ASME 2002 International Design Engineering Technical Conferences and Computers and Information in Engineering Conference, pages 567-577. American Society of Mechanical Engineers, 2002.

[48] A Bejan, S Lorente, and A Miguel. Constructal human dynamics, security and sustainability.

[49] G W Merkx. Flow systems, catastrophes, and public policy. Constructal Human Dynamics, Security and Sustainability, 50:37, 2009.

[50] A Bejan, JD Charles, and S Lorente. The evolution of airplanes. Journal of Applied Physics, 116(4):044901, 2014.

[51] P Mardanpour, E Izadpanahi, S Rastkar, S Lorente, and A Bejan. Constructal design of aircraft: Flow of stresses and aeroelastic stability. AIAA Journal, pages 1-13, 2018.

[52] P Mardanpour and D H Hodges. On the importance of nonlinear aeroelasticity and energy efficiency in design of flying wing aircraft. Advances in Aerospace Engineering, $2015,2015$.

[53] D H Hodges. Nonlinear composite beam theory. Progress in astronautics and aeronautics, 213:304, 2006.

[54] D A Peters, S Karunamoorthy, and W-M Cao. Finite state induced flow models. i-twodimensional thin airfoil. Journal of Aircraft, 32(2):313-322, 1995.

[55] Z Sotoudeh, D H Hodges, and C-S Chang. Validation studies for aeroelastic trim and stability of highly flexible aircraft. Journal of Aircraft, 47(4):1240-1247, 2010. 
[56] M Goland and YL Luke. The flutter of a uniform wing with tip weights. Journal of Applied Mechanics, 15(1):13-20, 1948.

[57] P Mardanpour, D Hodges, $\mathrm{R}$ Neuhart, and $\mathrm{N}$ Graybeal. Effect of engine placement on aeroelastic trim and stability of flying wing aircraft. In 53rd AIAA/ASME/ASCE/AHS/ASC Structures, Structural Dynamics and Materials Conference 20th AIAA/ASME/AHS Adaptive Structures Conference 14th AIAA, page 1634, 2012.

[58] P Mardanpour, P W Richards, O Nabipour, and D H Hodges. Effect of multiple engine placement on aeroelastic trim and stability of flying wing aircraft. In 54th AIAA/ASME/ASCE/AHS/ASC Structures, Structural Dynamics, and Materials Conference, page 1571, 2013.

[59] P Mardanpour, D H Hodges, and R Rezvani. Nonlinear aeroelasticity of high-aspectratio wings excited by time-dependent thrust. Nonlinear Dynamics, 75(3):475-500, 2014.

[60] P Mardanpour, E Izadpanahi, S Rastkar, and D H Hodges. Effects of engine placement on nonlinear aeroelastic gust response of high-aspect-ratio wings. In AIAA Modeling and Simulation Technologies Conference, page 0576, 2017.

[61] P Mardanpour, E Izadpanahi, S Rastkar, and D H Hodges. Nonlinear aeroelastic gust suppression and engine placement. Journal of Aircraft, 54(6):2402-2404, 2017.

[62] M J Patil and D H Hodges. Flight dynamics of highly flexible flying wings. Journal of Aircraft, 43(6):1790-1799, 2006.

[63] C-S Chang, D H Hodges, and M J Patil. Flight dynamics of highly flexible aircraft. Journal of Aircraft, 45(2):538-545, 2008.

[64] E Izadpanahi and P Mardanpour. Nonlinear aeroelastic response of highly flexible flying wing due to different gust loads. In Mahmut Reyhanoglu, editor, Nonlinear Systems, chapter 5, pages 89-106. IntechOpen, 2018.

[65] P Mardanpour, E Izadpanahi, S Rastkar, S Calastawad, and C Levy. Effect of shooting and blast-induced gust on nonlinear aeroelastic stability and behavior of high-aspect ratio wing. Journal of Sound and Vibration, 433:299-313, 2018.

[66] C Geuzaine and J-F Remacle. Gmsh: A 3-d finite element mesh generator with builtin pre-and post-processing facilities. International journal for numerical methods in engineering, 79(11):1309-1331, 2009.

[67] W Yu, V V Volovoi, D H Hodges, and X Hong. Validation of the variational asymptotic beam sectional analysis. AIAA journal, 40(10):2105-2112, 2002. 
[68] W Yu and D H Hodges. Generalized timoshenko theory of the variational asymptotic beam sectional analysis. Journal of the American Helicopter Society, 50(1):46-55, 2005.

[69] W Yu, D H Hodges, and J C Ho. Variational asymptotic beam sectional analysis-an updated version. International Journal of Engineering Science, 59:40-64, 2012.

[70] W Yu, D H Hodges, V Volovoi, and C ES Cesnik. On timoshenko-like modeling of initially curved and twisted composite beams. International Journal of Solids and Structures, 39(19):5101-5121, 2002. 